\title{
A gênese do imposto sobre o valor agregado
}

\author{
Ubaldo Cesar Balthazar*
}

Resumo: Este artigo tem como objetivo analisar a história do princípio das deduções, ínsito ao Imposto sobre o Valor Agregado, a partir de uma análise de textos das doutrinas francesa e belga, principalmente. Procura demonstrar que, ao contrário do que pretendem autores franceses, o citado princípio não foi pensado originalmente na França, mas foi antes produto de um processo evolutivo registrado em vários ordenamentos positivos. Em um segundo momento é estudada a instituição do IVA francês, verificando-se os avanços e recuos, as dificuldades encontradas no longo processo de consolidação do imposto naquele país. Com isso pretende-se oferecer uma reflexão à doutrina brasileira, no momento em que se discute a instituição de um imposto sobre o valor agregado no direito positivo pátrio.

Palavras-chave: Imposto, Princípio de deduções, História do imposto, Regra do buttoir, Valor agregrado.
Summary: The objective of the article is to analyze the history of the principles of deduction, in accordance with the 'Tax on Added Value', and primarily from an analysis of texts of the French and Belgian doctrine. The article will demonstrate that, in contrast of intend French authors, cited principle was not thought originally in France, but rather a registered evolutionary process in some positive orders. Secondly, the French institution IVA will be studied, assessing its pros and cons as well as looking at the difficulties found in the long process of tax consolidation in that country. This is intended to offer a reflection of the corresponding Brazilian doctrine, when it is being discussed the imposition of a 'Tax on Added Value' in the native positive law.

Keys-words: Tax, Principle of deduction, Tax History, Buttoir rule, Added value.

O estudo do Imposto sobre o Valor Agregado (IVA) exige uma análise de sua evolução, sua história, com especial atenção à literatura jurídica tributária francesa, eis que foi nesse país que o imposto nasceu e progressivamente se desenvolveu, adquirindo os traços que conhecemos atualmente. Para conhecer o seu mecanismo precisamos pesquisar suas origens, para saber como e por que atingiu o desenvolvimento que tem hoje, adotado não só na União Européia mas em vários outros países europeus, sul-americanos e asiáticos.

Em primeiro lugar é importante observar que o mecanismo de deduções, que constitui o princípio de base do imposto, ainda que adotado pela legislação de 1948, não foi invenção francesa ${ }^{1}$. A este respeito devemos lembrar a contribuição da doutrina e certas legislações estrangeiras ao desenvolvimento do princípio, e isso bem antes da aplicação do mesmo na França.

\footnotetext{
* Professor de Direito Tributário da UFSC. Doutor em Direito Fiscal pela Universidade Livre de Bruxelas, Bélgica.
} 
A doutrina francesa, em geral, quando analisa as origens do IVA, situa o início das imposições sobre o volume dos negócios na França em 1917, com a instituição da "taxa sobre os pagamentos", imposto geral sobre as despesas e do qual, após certo número de reformas, o resultado foi o IVA, com sua técnica e seus mecanis$\operatorname{mos}^{2}$. O princípio da dedução aparece então como uma conseqüência natural da evolução do imposto. A contribuição da doutrina tributária estrangeira, assim como as aplicações legislativas do imposto atingindo o valor adicionado das empresas no estrangeiro, conserva na França uma fraca importância em relação à sua verdadeira influência sobre a formulação, nesse país, de uma teoria de imposição sobre o valor adicionado.

Alain Frankel, autor do estudo mais aprofundado sobre as origens do imposto na França ${ }^{3}$, mostra bem a influência que exerceu sobre o pai intelectual do IVA naquele país, Maurice Lauré, a doutrina estrangeira - notadamente as teorias do professor Carl S. Shoup, dos Estados Unidos ${ }^{4}$. Frenkel, aliás, analisa as primeiras proposições de uma imposição sobre o valor agregado em empresas dos Estados Unidos da América e da Alemanha, e a tentativa de aplicação de um imposto incidente sobre o valor agregado no Japão ${ }^{5}$, citando ainda alguns casos de uma aplicação dessas teorias no direito positivo da Grécia, da Turquia e da Argentina. Descarta, entretanto, a possibilidade de uma influência maior dessas legislações na formulação do projeto francês ${ }^{6}$.

Se o princípio foi retido pela legislação francesa, que o conjugou com o princípio da neutralidade econômica, próprio do imposto ${ }^{7}$, ele não foi, porém, o resultado

\footnotetext{
${ }^{1}$ Assim, por exemplo, quando M.Coziani ("Lês Dessous de la TVA”, Librairie A.Colin, Paris, 1971, p. 9) afirma que "o IVA é um mecanismo engenhoso, de invenção francesa, plagiado hoje no estrangeiro", devemos compreender seu comentário como se referindo à estrutura do tributo com seus princípios, mas não ao mecanismo de deduções. Com efeito, este foi aperfeiçoado pelo legislador francês a partir de uma longa evolução doutrinária e legislativa estrangeira.

${ }^{2}$ Podemos citar, entre outros, M. Lauré, "La TVA" (Paris, Fança, 1952); G. Egret, La TVA française, in "La reforme de nos impôts indirects et la TVA" (Chambre de Commerce de Bruxelles, Rec.de conférences, 1967, pp.31-49); M. Frapsauce, "La TVA", conférence donée lê 27 mars 1963, Institut Belge de Finances Publiques (Bulletin de Doc. n. 2, 1964, edite par lê Service d'Etudes et de Documentation du Ministère de Finances); François Lefebre, "La nouvelle TVA", ed. F. Lefebre, 1967.

3 "La genèse de la taxe sur la valeur ajoutée", tese, Paris, 1976.

${ }^{4}$ Op.cit., pp. 322-325. Apenas a título de curiosidade, lembramos a influência exercida por Shoup na reforma tributária brasileira de 1965 (EC n. 18/65), resultado direto do Seminário sobre Reforma Tributária realizado pela Fundação Getúlio Vargas, em São Paulo, em agosto de 1964 (Cf."Seminário sobre Reforma Tributária”, FGV, 1965).

${ }^{5}$ Op. cit., pp. 299-318.

${ }^{6}$ Op. cit., nota 14, p. 235.

${ }^{7} \mathrm{O}$ que, de fato, constituiria a originalidade do imposto (cf. também A. Frenkel, op.cit., Introdução, p. IX).
} 
de uma evolução que o mesmo tenha conhecido na França. Ainda em 1921, Wilhelm Von Siemens, industrial alemão, propôs a substituição da "Umsatzteuer", então em vigor, por uma "Vereldelte Umsatzteuer", um imposto mais puro sobre o volume dos negócios.

Von Siemens introduziu, em sua proposição, o princípio da dedução, o qual deveria ser feito "base sobre base". Trata-se, provavelmente, de um dos primeiros estudos nessa área, ao lado do efetuado pelo economista norte-americano Thomas Adam. Este publicou um artigo no qual defendeu a aplicação do princípio de deduções num sistema de imposto sobre o volume dos negócios (IVN), dedução que deveria ser feita "imposto sobre imposto", ou seja, o mesmo mecanismo finalmente adotado pelo legislador francês do IVA.

Lembremos ainda que o princípio teve aplicações legais na Turquia, Grécia e Argentina. A Turquia estabeleceu a dedução "imposto sobre imposto", enquanto que o legislador grego adotou a dedução "base sobre base". No projeto japonês, datado de 1949, estava prevista a aplicação de um sistema de deduções "base sobre base", o qual, ainda que aprovado pelo Parlamento, nunca foi aplicado ${ }^{8}$. Importa citar ainda o caso do Estado de Michigan, nos Estados Unidos, que adotou em 1953 o "Business Activities Tax", no qual a dedução seria feita "base sobre base".

No entanto, esses projetos, estudados pela doutrina ${ }^{10}$, desenvolveram o princípio baseado em um sistema de imposto atingindo a empresa, e não os produtos que ela fabricasse. Em outras palavras, o imposto concebido pela doutrina americana e alemã, e adotado por alguns países, possuía como base de cálculo a margem bruta ou valor agregado da empresa, não atingindo seus produtos ou serviços ${ }^{11}$.

O mecanismo de deduções, portanto, já existia, mesmo que pensado e aplicado de forma diferente da consagrada na França. Os projetos franceses se desenvolveram de maneira bem específica, obedecendo às exigências e premissas das reformas conjunturais promovidas em um quadro econômico, político e social bem determinado. Resta evidente, portanto, que o mecanismo de deduções, pilar do sistema do IVA, não nasceu na França. Se o imposto é uma "invenção" francesa, devemos entender com isso que é o resultado de uma conjugação de elementos

\footnotetext{
${ }^{8}$ Frenkel, op. cit., p. 313.

${ }^{9}$ W. de Clercq, "L'harmonisation de la taxe sur le chiffre d'affaires dans le cadre do Marché Commun", in PFD, 5ème.série, Bruxelles, 1975, p. 19.

${ }^{10}$ Egret ("La TVA", cit., p.20), lembra ainda o trabalho de M. Julien Roger, auditor de tributos francês, intitulado "La taxe sur les plus values", publicado em 1936 (texto que foi posteriormente analisado por Frenkel, em sua tese de doutoramento. Op. cit., pp. 235 e segs.).

${ }^{11} \mathrm{O}$ que constituiria uma espécie de imposto profissional no qual as modalidades de cálculo não permitiriam a menção sobre as faturas, uma repercussão nos preços, a transmissão aos outros contribuintes nem o reembolso em caso de exportação (Egret, op. cit., p. 20).
} 
como a hipótese de incidência e a exigibilidade, a base de cálculo, o campo de aplicação, a definição do contribuinte e a formulação de um mecanismo próprio de deduções.

Difícil aceitar, dessa forma, que o mecanismo geral de deduções tenha surgido apenas em função das experiências francesas, pois, como vimos, houve anteriormente estudos e aplicações em outros direitos positivos. A doutrina, em outros ordenamentos, já havia abordado o assunto, não se tratava de um princípio desconhecido. Até mesmo a afirmação segundo a qual a técnica de dedução "imposto sobre imposto", aplicada na Turquia em 1927, teria sido uma redescoberta dos funcionários do Fisco francês - os quais buscavam remediar os defeitos da dedução base sur base $\mathrm{e}^{12}$ - nos parece um pouco excessiva.

Dessa forma, não foram o acaso ou as contingências de uma evolução na França que fizeram nascer o princípio de deduções do IVA. A doutrina havia já desenvolvido o mesmo em grande parte, tendo sido aplicado nas legislações de alguns poucos países. Era um princípio já conhecido.

Resta claro que foi na França que, como conseqüência das reformas realizadas durante mais de 40 anos, apresentaram-se as condições para a instauração do imposto sobre o valor agregado, com seus elementos e características tais como conhecemos hoje. O grande mérito do legislador francês foi ter sabido conjugar todos os elementos que resultaram da evolução do sistema de imposição do volume de negócios, construindo os contornos próximos do sistema atualmente aplicado por todos os Estados membros da União Européia.

Após efetuarmos essa digressão sobre o nascimento e desenvolvimento do princípio de deduções, ínsito ao IVA, cabe refletir sobre a história do imposto, este sim pensado, aplicado e desenvolvido na França. Como vimos, o trabalho mais completo sobre a gênese do IVA na França foi o de Alain Frenkel. O autor estudou a evolução dos impostos sobre o volume dos negócios em seu país de forma profunda, mostrando todos os caminhos e propostas feitas pelo legislador, as vitórias e os fracassos das reformas efetuadas. Segundo ele, o resultado do processo, o Imposto sobre o Valor Agregado, foi o resultado direto das experiências aos quais se entregaram os franceses; ordenamento positivo algum teria conhecido tal desfilar de sistemas nem realizado tantas pesquisas para atingir finalmente, como resultado, $o$ IVA $^{13}$.

Com efeito, o IVA é o resultado de uma longa evolução: o início do processo pode ser identificado com a Lei de 31 de dezembro de 1917, que instituiu a "taxa

\footnotetext{
${ }^{12}$ Frenkel, op. cit., p. 265.

${ }^{13}$ Frenkel, op. cit., Introdução, p. IX.
} 
sobre os pagamentos"14. Esse tributo se constituía em um imposto sobre faturas, bastante próximo de um imposto sobre as transmissões aplicado na vizinha Bélgica até 1970: o contribuinte o quitava com a aposição de selos sobre as faturas. O imposto incidia sobre os pagamentos privados comprovados escrituralmente e as vendas a varejo a uma alíquota de $0,20 \%{ }^{15}$.

Esse novo imposto, criado para obtenção de novas receitas fiscais para o Estado $^{16}$, não teve o rendimento esperado, "em razão de uma técnica de recolhimento arcaica e de fraudes importantes" ${ }^{17}$. Além do mais, o tributo provocou muitos protestos, traduzidos em vários recursos junto aos poderes públicos ${ }^{18}$.

As necessidades orçamentárias, principalmente, aceleraram o fim do referido imposto. A Lei de 25 de janeiro de 1920 criou, então, um novo imposto sobre o valor dos negócios, atingindo todas as transações comerciais, nelas compreendendo as prestações de serviços, a uma alíquota de $2 \%$. Era um imposto cumulativo, que incidia sobre cada transação, desde o primeiro estágio da produção até a última fase da distribuição.

Os contribuintes eram principalmente os industriais e os comerciantes, afastando dessa forma as profissões liberais e os agricultores de seu campo de aplicação. A alíquota geral, originalmente de $1,1 \%$, foi fixada pouco tempo depois em $2 \%$. Alguns produtos, entretanto, sofriam uma incidência a uma alíquota majorada de $10 \%$, outros à alíquota reduzida de 1,30 ou $0,55 \%$, enquanto outros eram exonerados do imposto. ${ }^{19}$

Se a "taxa sobre os pagamentos" não passou de uma rápida experiência ${ }^{20}, \mathrm{o}$ IVN foi determinante para todas as reformas efetuadas posteriormente, pois fixou os limites e os princípios dos impostos criados ou modificados desde então ${ }^{21}$. Podemos citar, a respeito desse imposto, duas características principais: o sujeito passivo, definidos pela lei de 1920 , são os mesmo até hoje ${ }^{22}$, e o princípio de imposição "imposto incluso" 23 foi mantido por um longo tempo pela legislação francesa.

\footnotetext{
${ }^{14}$ Para a história e as características desse tributo, v. Frenkel,op. cit., pp. 1-26.

${ }^{15}$ Seriam $10 \%$ nos casos de despesas suntuárias (cf."Sixième Rappport ao Président de la Republique", Conseil des Impôts, Journaux Officiels, Paris, 1983, p. 8).

${ }^{16}$ G. Vedel, "Vue general sur le système fiscal français ", FMC, 1962-2, p. 40.

17 "Sixième rapport...", op. cit., p. 8.

${ }^{18}$ Egret, op. cit., p.32.

19 "Sixième rapport...", cit., p. 8.

${ }^{20}$ M. Frapsauce, op. cit., p. 4.

${ }^{21}$ Egret, op. cit., p. 8.

${ }^{22}$ Nele compreendida a noção de explorador agrícola.

${ }^{23}$ Trata-se do conhecido sistema pelo qual o imposto faz parte da base de imposição do produto tributado.
} 
O sistema funcionou razoavelmente bem durante certo tempo, devido à alíquota moderada de $2 \%$. Pouco a pouco, porém, operou-se uma evolução, principalmente em função da falta de neutralidade do imposto (em razão principalmente de seu efeito cumulativo). $\mathrm{O}$ excessivo número de devedores teve igualmente uma conseqüência desfavorável, trazendo problemas de controle; a ausência de controles favorecia a fraude, sendo a mais comum a que transformava os comerciantes em prestadores de serviços (a base das prestações de serviços sendo o montante das comissões, enquanto que a base de cálculo, para as vendas de bens, era o preço da transação $)^{24}$.

Uma resistência do comércio, principalmente do varejista, que tendia a rejeitar a carga fiscal sobre a indústria ${ }^{25}$, resultou na instauração de "impostos únicos" já a partir de 1925. Assim, uma série de produtos foi subtraída do imposto geral sobre o valor dos negócios, sendo atingida por um imposto único, incidindo uma única vez, em um estágio determinado do circuito de produção. Os impostos únicos foram aplicados principalmente no setor de alimentação, através de alíquotas variáveis entre 8 e $12 \%$.

A característica mais importante dos impostos únicos residia em sua incidência na fase final de produção, o que fez aparecer a noção de produtor. Na evolução do sistema, tal noção seria utilizada no circuito do "imposto sobre a produção" imposto que, de fato, situa-se na origem imediata do IVA ${ }^{27}$.

A existência de impostos únicos, mais de trinta ${ }^{28}$, ao lado do imposto sobre o valor dos negócios, teve como resultado uma complexidade muito grande do sistema, já que este último continuava a ser aplicado nos setores não alcançados pelos impostos únicos e mesmo incidindo de forma cumulativa com eles. ${ }^{29}$ Essa mistura de tributos, a imbricação com o IVN, resultaram na reforma de 1936, quando a Lei de 31 de dezembro suprimiu este último e a maioria dos impostos únicos, substituindo-os por um "imposto único global sobre a produção".

Esse imposto, cobrado inicialmente a uma alíquota de 6\%, incidia uma única vez sobre os produtos tributados, em um momento determinado de seu ciclo de produção. Tal estágio, escolhido pelo legislador para fazer incidir o imposto, foi o

\footnotetext{
${ }^{24} \mathrm{Ch}$. Campet, "Le regime fiscal du chiffre d'affaaires et son incidence sur le productivité", publié par l’Agence Européenne de Productivité de l'OECE, Paris, 1957, p. 47.

${ }^{25}$ Lefebre, op. cit., p. 9.

${ }^{26}$ Egret, op. cit., p. 33.

${ }^{27}$ Lefebre, op. cit., p. 9.

${ }^{28}$ Foram criados 35 impostos únicos a partir de 1925 e até 1936 (cf. Lefebre, op. cit., p. 9), incidindo, entre outros, sobre carvão, chá, café, açúcar, bebidas, perfumaria e automóveis.

${ }^{29}$ Lefebre, idem.
} 
último, o da industrialização, precedendo a comercialização ("estágio do último produtor fiscal") $)^{30}$. Os bens eram exonerados do imposto na fase de distribuição, o que fez diminuir pela metade o número de devedores do imposto em relação ao sistema anterior, de 1925. As prestações de serviços, assim como as vendas de produtos consumidos no interior do estabelecimento, tributadas a uma alíquota de $2 \%$, continuavam submetidas ao IVN de 1920, mantido com um campo de aplicação limitado ${ }^{31}$.

Considerando o regime de pagamentos, restrito a uma só operação do ciclo de produção e de comercialização, todo o circuito industrial anterior à imposição não era alcançado pelo imposto. Matérias-primas e produtos acabados eram exonerados pela aplicação do regime então denominado "em suspensão do imposto", significando que os produtores situados nas fases anteriores à percepção do imposto podiam se abastecer, em regime de suspensão, de matérias-primas e de produtos incorporados fisicamente nas mercadorias tributadas. Em tais situações, eles deveriam entregar aos seus fornecedores atestados pelos quais se comprometiam a entregar seus produtos a um outro produtor ou a pagar eles mesmos o imposto.

Esse regime implicava de fato uma dedução física das matérias-primas e dos produtos a elas assimilados, o que provocava uma dupla imposição para outros bens que entram igualmente da estrutura de um preço (equipamentos, bens de investimento, despesas gerais): na medida em que o contribuinte pagava o imposto incidente sobre esses bens, sem poder deduzi-lo, esse imposto tornava-se um elemento de seu preço de revenda que, por sua parte, constituía a base do imposto da qual era devedor. Evidente, portanto, que o imposto conservava um caráter cumulativo, incidindo duas vezes sobre o valor dos bens e dos serviços intermediários.

Daí que esse regime em pouco tempo demonstrou seus inconvenientes, pois fazia cair o peso do imposto sobre um só contribuinte, o último produtor. $\mathrm{O}$ aumento da alíquota nada mais fez que agravar o problema, incitando o sujeito passivo à fraude. De fato, o sistema repousava sobre a solvabilidade e a honestidade de um só contribuinte ${ }^{32}$.

Além dessa dificuldade, vários outros problemas ligados à aplicação do imposto apareceram, como o da carga final suportada pelo consumidor, a qual variava em função das margens do circuito de distribuição. Assim, dois produtos idênticos poderiam chegar à fase final de comercialização com preços diferentes, tudo dependendo do tamanho do circuito econômico percorrido antes de chegar ao "último produtor". Outro problema lembrado pela doutrina ${ }^{33}$ refere-se ao "vazio fiscal" que

${ }^{30}$ Sixième rapport...”, cit., p. 8.

31 "Sixième rapport...", idem.

32 "Sixième rapport...", cit., p. 8.

${ }^{33}$ Lefebre, op. cit., p. 9. 
o sistema criava no circuito de produção, distribuição e comercialização dos produtos. Isso levou o governo a propor a criação, em 1939, de um "imposto sobre as transações", a ser pago pelo comércio, ao lado de um "imposto local”, instituído em 1942 e cobrado em proveito dos municípios ${ }^{34}$.

O imposto sobre as transações, criado em 21 de abril de 1939 sob a denominação de "imposto de armamento", incidia, a uma alíquota de 1\%, sobre todas as vendas. Era um imposto cumulativo, que aumentou o número de contribuintes. $\mathrm{O}$ imposto local, originalmente deixado à iniciativa dos municípios, que podiam ou não instituí-lo, tornou-se de cobrança obrigatória a partir de 1948. Incidia, a uma alíquota de $1,75 \%$, sobre todas as operações não alcançadas pelo imposto sobre a produção.

Em função disso, o sistema era objeto de fortes críticas, visto não ser nem mesmo "único", provocando efeitos cumulativos bastante pesados para o último produtor. Para remediar, a Lei de 24 de setembro de 1948 promoveu uma importante reforma referente ao imposto sobre a produção, com a instauração dos pagamentos fracionados, e, via de conseqüência, suprimiu o regime de suspensão de imposto.

No novo regime, o imposto seria pago em todas as etapas que o produto passasse, conforme o número de transações sofridas no processo de sua evolução. O operador econômico contribuinte do imposto deveria pagá-lo calculando-o sobre o valor de suas vendas, mas poderia deduzir o tributo pago sobre o montante de suas compras de matérias-primas e de "produtos similares" integrados fisicamente no produto que fabricava ${ }^{35}$. Este regime instaurou, portanto, um dos princípios fundamentais do futuro IVA, embora limitado ainda às deduções físicas.

Curioso notar que a aplicação dos pagamentos fracionados foi uma conseqüência dos problemas orçamentários franceses e do desejo de acelerar a entrada do imposto aos cofres públicos ${ }^{36}$. Segundo cálculo de autoridades fiscais da época, a substituição do sistema suspensivo pelo novo sistema teria permitido ao Estado receber 20 bilhões de francos a mais de receita, por mês, durante os três primeiros meses, sem aumento das alíquotas do imposto sobre a produção. Aliás, tal fato foi o principal argumento para justificar a reforma então realizada.

O raciocínio era aparentemente bem-fundado: "O imposto não seria mais percebido somente no início do processo de produção; ele incidiria igualmente o produto desde os primeiros estágios de sua elaboração, sendo seu recolhimento, desta forma, antecipado e acelerado". ${ }^{37}$ Contudo, na perspectiva de um imposto pago

\footnotetext{
34 “Une taxe perçue au profit des collectivités locales" (Lefebre, idem). Esses dois impostos foram unificados em 1955 e afetados aos orçamentos locais (Lefebre, idem).

${ }^{35}$ Ch. Campet, op. cit., p. 472.

${ }^{36}$ Para conhecer mais a história desta reforma, v. Frenkel, op. cit., pp. 259-296.

${ }^{37}$ Frankel, idem.
} 
desde o início do ciclo de produção, o Fisco francês esqueceu-se de um detalhe fundamental: todos os contribuintes adquiriram o direito de deduzir, do imposto incidente sobre suas vendas, o imposto pago sobre suas compras, o que anulava a possível vantagem com que contavam as autoridades fiscais.

Dessa forma, o que deveria ter se constituído num aporte de receita, revelouse, em função de seu mecanismo, um simples meio de repartir a carga do imposto entre todos os operadores econômicos contribuintes ${ }^{38}$ no lugar de obrigar ao pagamento somente o último produtor.

Os pagamentos fracionados se revelaram, dessa forma, ineficazes enquanto meio de acelerar o incremento do imposto. Foi Maurice Lauré, à época Inspetor de Finanças e conselheiro técnico no Gabinete do Secretário de Estado de Finanças, quem percebeu o problema e teve a idéia de instituir, no decreto de aplicação da Lei de 24/09/1948, a regra da diferença de um mês nas deduções ${ }^{39}$.

Essa regra, vigente ainda hoje na França, obriga os contribuintes a somente efetuar a dedução do imposto pago sobre suas compras sobre o que devem recolher ao Fisco, a título de suas vendas, no mês seguinte. Trata-se de um expediente que permitiu ao Tesouro recolher, no primeiro mês de instauração do sistema, um imposto suplementar "incidente" sobre as compras de todos os produtores ${ }^{40}$. A regra foi suprimida em 1965 para as deduções relativas aos investimentos ${ }^{41}$, mas foi mantida para todos os outros bens e serviços submetidos ao imposto ${ }^{42}$.

\footnotetext{
${ }^{38}$ É de se perguntar se teria havido uma reforma de tal monta se a Administração fiscal francesa tivesse previsto que não haveria vantagem alguma depois de quatro ou cinco meses... É uma questão que chama a atenção, colocando em evidência a dependência das reformas tributárias aos problemas conjunturais, orçamentários, dos Estados em geral.

${ }^{39}$ Frenkel, op. cit., p. 284.

${ }^{40}$ Frankel, idem.

${ }^{41}$ Egret, "La TVA", cit., p. 71. André Voisin, deputado francês, apresentou em 1965 um projeto para revogar a regra. O governo, por intermédio do Ministro de Finanças, opôs-se, argumentando que tal proposta "se traduziria numa perda de receita de ordem de três bilhões de francos". Voisin, porém, não via nem sua proposta uma perda de receita, mas simplesmente "um atraso na entrada de fundos". O projeto, entretanto, não foi aprovado (J.O. Débats parlementaires. Assembléia Nacional, 26 de junho de 1965, pp. 2508-2509).

${ }^{42}$ Segundo certas estimativas, tais avanços de tesouraria representariam cerca de 78 bilhões de francos em 1990 (cf. Jean Lafourcade, "Les freins à l'harmonisation des TVA européennes", in Revista "Gazette du Palais", 1990, 1. semestre, p. 314), tornando assim bastante difícil a supressão total da regra, tal como foi prevista pela $6^{a}$ Diretiva IVA/CEE. O desenvolvimento dos negócios e a inflação fizeram aumentar ainda mais tal receita, impedindo o governo de revogar plenamente essa famosa regra do direito fiscal francês. Ver, a propósito, o art. 34 do vigente Código francês dos TCA ("Taxes sur le Chiffres d'Affaires"): "Sauf en cas d'exportation ou de livraison de bien et services dont l'acquisition ou l'importation en franchise est autorisée, la déduction précitée ne peut aboutir à un remboursement, même partiel de la taxe" (Ver "Limitation du droit à déduction. La règle du Butoir", in: <http://www.impots-dz.org/COURS/sit_tva/tva18.htm>. Acesso em: 7 mar. 2008. )
} 
A instauração do sistema de pagamentos fracionados suscitou também a "théorie du butoir"43, abandonada quando da reforma do IVA em 1968 ${ }^{44}$, mas aplicada na França até 1972. Somente depois o crédito do imposto pôde ser reembolsado por pedido expresso do contribuinte. A regulamentação, entretanto, proibiu os reembolsos integrais dos créditos anteriores a 1972, enquanto que, para aqueles posteriores a esta data, os reembolsos foram limitados por um crédito de referência. Tal disposição "criou uma distorção em detrimento das empresas antigas, em relação às empresas mais novas" 45 .

Entretanto, não havia qualquer dúvida de que o regime dos pagamentos fracionados era mais vantajoso que o regime anterior, e isso por várias razões. É preciso lembrar, entre outras, que o sistema satisfazia o Tesouro face aos riscos de fraude ou de falhas, pois as cargas fiscais eram repartidas entre todos os operadores econômicos partícipes do ciclo de produção de um determinado produto.

O sistema facilitava também, através do jogo de faturas, as verificações úteis para o controle fiscal, da mesma forma que, ao evitar definir o "último produtor fiscal", simplificava a manutenção da contabilidade pelos produtores contribuintes, que não precisavam mais verificar se tinham ou não de quitar o imposto em função da qualidade de seus clientes ${ }^{46}$.

Seu principal defeito, contudo, era a falta de neutralidade, pois ele continuava a incidir duplamente sobre os investimentos e as despesas gerais da empresa. Se o sistema funcionava bem para a dedução de elementos físicos constitutivos do produto tributado, os elementos ditos "financeiros", isto é, os investimentos e as despesas gerais que compunham também o preço de revenda, não podiam ser deduzidos. Isso era considerado uma anomalia, numa época em que a preocupação com a produtividade era preponderante ${ }^{47}$.

É necessário acrescentar a isso a existência, ao lado do imposto sobre a produção, de três impostos cumulativos - o imposto sobre as prestações de serviços, o imposto sobre as transações e o imposto local -, o que alterava a unidade do siste$\mathrm{ma}^{48}$. Além do mais, desde 1951 o legislador francês havia restabelecido novos impostos únicos, específicos, incidindo sobre os vinhos e as carnes. Importante no-

\footnotetext{
${ }^{43}$ Aplicação de um teto para deduções. Para análise dessa regra, v. Jean-Roger Kauffman, La nouvelle TVA, le regime définitif, in "La réforme de la TVA - incidences immédiates et perspectives d'avenir", DUNOD, Paris, 1969, p. 18.

${ }^{44}$ Kauffman, op. cit., p. 18.

${ }^{45}$ Cf. Egret, op. cit., pp. 70-71.

46 "Sixième rapport...", op.cit., p. 9.

${ }^{47}$ Sobre o movimento em favor de produtividade na França e sua influência sobre a formulação de uma teoria do IVA, v. Frenkel, op. cit., pp. 318-325.

48 “Sixième rapport...", cit., p. 9.
} 
tar, apenas para registro, que em 1956 foram criados novos impostos análogos, atingindo o café, o chá e veículos de transporte de mercadorias ${ }^{49}$.

Todos esses problemas, reunidos, tiveram como conseqüência a extensão do sistema de deduções aos investimentos (embora limitados à metade do imposto que tivessem gravado) $)^{50}$, a partir de setembro e outubro de 1953. Isso não significava ainda a instauração do IVA. Tratava-se de uma medida temporária (seis meses) destinada a estimular os investimentos. Constituía, entretanto, "um primeiro passo em direção à adoção do IVA, limitando, contudo, o custo orçamentário"51.

Foi apenas em 1954, com a Lei de 10 de abril, que o IVA foi instituído ${ }^{52}$, após várias tentativas infrutíferas levadas a efeito pelos sucessivos governos que a França conheceu entre 1952 e $1954^{53}$. A adoção do IVA foi marcada, de um lado, por limitações orçamentárias que frearam a reforma fiscal então pretendida ${ }^{54}$, enquanto de outra parte os imperativos econômicos de ordem estrutural e conjuntural contribuíram de maneira preponderante para a instauração da base de cálculo do imposto em 1954: se o fenômeno da dupla tributação dos investimentos "constituía um handicap estrutural à modernização do aparelho produtivo francês", a depressão econômica durante os anos 1952-1952, e a necessidade de uma reativação do investimento, resultaram na adoção do IVA, então considerado como um instrumento privilegiado de retomada do crescimento econômico ${ }^{55}$.

Estes são os fatos e incidentes que estão na gênese do IVA francês, hoje um modelo de tributação adotado em vários Estados, a começar pelos 27 países membros da União Européia. Após 1954, muitos outros diplomas normativos tiveram que ser editados no ordenamento positivo francês para resolver os múltiplos problemas resultantes da adoção do novo imposto. Como bem lembrou Lauré, em obra de 1957, a lei de 10 de abril de 1954 promoveu uma reforma apenas do imposto sobre a produção ${ }^{56}$. Subsistiam ainda o imposto sobre a prestação de serviços, o imposto

\footnotetext{
${ }^{49}$ Idem.

${ }^{50}$ Decreto 53.942, de 30/09/1953.

51 "Sixième rapport...", cit., p. 9.

52 De notar o papel importante desempenhado por Maurice Lauré para a adoção do imposto na França. Ver, a esse respeito, Frenkel, op. cit., pp. 326-349.

${ }^{53}$ Foram os governos Pinay, em 1952, René Mayer, em 1953, e Joseph Laniel, também em 1953. Para a análise dos projetos apresentados, assim como para o estudo do projeto finalmente adotado pela Assembléia Nacional francesa, ver Frenkel, op. cit., pp. 387-411.

${ }^{54}$ Fato que pode explicar o caráter limitado das reformas submetidas ao Parlamento e a adoção, por este, de um método por etapas sucessivas, que permitia o aumento apenas progressivo das alíquotas do IVA. Desta forma, a instauração do imposto, em 1954, "não exerceu praticamente qualquer influência sobre os preços" (cf. Frenkel, op. cit., p. 442).

${ }^{55}$ V. Frenkel, op. cit., pp. 444-451.

${ }^{56}$ Lauré, “Au secours de la TVA”, Paris, 1957, p. 10.
} 
sobre as transações e o imposto local. O primeiro foi, porém, ligado ao IVA: o contribuinte podia deduzi-lo do IVA, embora a recíproca não fosse autorizada,

Lauré, em sua obra, fez um balanço dos três anos de aplicação do imposto na França, reconhecendo que durante esse tempo, "o IVA empurrou, indiscutivelmente, nossa economia rumo à modernização" ${ }^{57}$. Seu trabalho, contudo, não foi feito para elogiar o IVA, mas para levantar todos os problemas que, em sua opinião, desnaturavam a boa aplicação do imposto: os regimes particulares, as situações pretensamente adquiridas, os sujeitos passivos, o índice de preços e a desconfiança da administração no que dizia respeito às escaladas de preços demagógicas.

Quando estamos novamente levantando a possibilidade de criar o IVA no Direito Tributário brasileiro, conhecer um pouco de sua origem poderá, quem sabe, fazer com que evitemos os erros cometidos pelo legislador francês, em sua longa caminhada rumo ao imposto considerado hoje, desde que bem aplicado, um forte fator de desenvolvimento econômico, sustentado pela transparência (facilitando a fiscalização), neutralidade (permitindo fixação de preços pelos agentes econômicos sem pressões fiscais) e redução da carga sobre o consumidor final (aquele que paga efetivamente o imposto).

\section{Referências}

CAMPET, Ch. Le regime fiscal Du chiffre d'affaaires et son incidence sur le productivité, publié par l'Agence Européenne de Productivité de 1'OECE, Paris, 1957.

CLERCQ, William de. L'harmonisation de la taxe sur le chiffre d'affaires dans le cadre do Marché Commun, in PFD, 5ème.série, Bruxelles, 1975.

COZIANI, M. Lês Dessous de la TVA, Librairie A.Colin, Paris, 1971.

EGRET, G. La TVA fançaise, in La reforme de nos impôts indirects et la TVA. Chambre de Commerce de Bruxelles, Rec.de conférences, 1967.

FRAPSAUCE, M. La TVA, conférence donée lê 27 mars 1963, Institut Belge de Finances Publiques. In Bulletin de Doc.n.2, 1964, edite par lê Service d'Etudes et de Documentation du Ministère de Finances.

FRENKEL, Alain. La genèse de la taxe sur la valeur ajoutée, tese, Paris, 1976.

KAUFFMAN, Jean-Roger. La nouvelle TVA, le regime définitif, in La réforme de la TVA - incidences immédiates et perspectives d'avenir, DUNOD, Paris, 1969.

${ }^{57}$ Lauré, op. cit., p.12. 
LAFOURCADE, Jean. Les freins à 1'harmonisation des TVA européennes, in Revista Gazette du Palais, 1990, $1^{\circ}$ semestre.

LAURÉ, Maurice. Au secours de la TVA, Paris, 1957. . La TVA. Paris, Fança, 1952.

LEFEBRE, François. La nouvelle TVA, ed. F. Lefebre, 1967.

VEDEL, George. Vue general sur le système fiscal français, FMC, 1962-2.

Fundação Getúlio Vargas. Seminário sobre Reforma Tributária, FGV, 1965.

J.O. Débats parlementaires. Assembléia Nacional, 26 de junho de 1965.

Limitation du droit à déduction . La règle du Butoir , in: $<$ http://www.impotsdz.org/COURS/sit_tva/tva18.htm>. Acesso em: 7 mar. 2008.

Sixième Rappport ao Président de la Republique, Conseil des Impôts, Journaux Officiels, Paris, 1983. 